\title{
Cytotoxicity analysis of gadolinium doped cerium oxide nanoparticles on human mesenchymal stem cells
}

\author{
A. L. Popov ${ }^{1}$, I. V. Savintseva ${ }^{1}$, E. A. Mysina ${ }^{1}$, A. B. Shcherbakov ${ }^{2}$, N. R. Popova ${ }^{1}$, \\ O. S. Ivanova ${ }^{3}$, D. D. Kolmanovich ${ }^{4}$, V. K. Ivanov ${ }^{3,5, *}$ \\ ${ }^{1}$ Institute of Theoretical and Experimental Biophysics, Russian Academy of Sciences, \\ Pushchino, Moscow region, 142290, Russia \\ ${ }^{2}$ Zabolotny Institute of Microbiology and Virology, National Academy of Sciences of Ukraine, \\ Kyiv D0368, Ukraine \\ ${ }^{3}$ Kurnakov Institute of General and Inorganic Chemistry of Russian Academy of Sciences, \\ Moscow 119991, Russia \\ ${ }^{4}$ Kabardino-Balkarian State University, Nalchik, 360004, Russia \\ ${ }^{5}$ Moscow Technological University, Institute of Fine Chemical Technologies, Moscow 119991, Russia \\ *van@igic.ras.ru
}

PACS 87.55.ne, 87.85.Rs, 81.07.Bc

DOI 10.17586/2220-8054-2018-9-3-430-438

\begin{abstract}
A complex analysis of cytotoxicity was performed for a nanodispersed sol of cerium dioxide doped with gadolinium $\left(\mathrm{Ce}_{0.8} \mathrm{Gd}_{0.2} \mathrm{O}_{2-\mathrm{x}}\right)$ using a culture of mesenchymal stem cells. The absence of cyto- and genotoxicity over a wide range of concentrations $\left(10^{-5}-10^{-9} \mathrm{M}\right)$ was demonstrated. At that, the highest concentration of $\mathrm{Ce}_{0.8} \mathrm{Gd}_{0.2} \mathrm{O}_{2-\mathrm{x}}$ nanoparticles $\left(10^{-4} \mathrm{M}\right)$ was found to slightly reduce the activity of intracellular dehydrogenase, yet not leading to the development of apoptosis and further cell death. The obtained results confirm a high degree of $\mathrm{Ce}_{0.8} \mathrm{Gd}_{0.2} \mathrm{O}_{2-\mathrm{x}}$ nanoparticle biocompatibility, which opens prospects for their safe application as a contrasting agent in the magnetic resonance tomography.
\end{abstract}

Keywords: ceria, gadolinium, nanomaterials, cytotoxicity, mesenchymal stem cells.

Received: 22 March 2018

\section{Introduction}

The modern level of nanotechnology development allows for the design of new polyfunctional materials possessing unique physicochemical properties that find wide application in the manufacturing of sensors [1,2], catalysts [3,4] hybrid functional coatings [5,6] and biomedical products [7]. At that, nanocrystalline cerium dioxide is considered to be one of the most promising materials for biomedical purposes [8-16]. To date, a broad variety of techniques and synthetic schemes is reported for the preparation of nanocrystalline cerium dioxide and for its surface modification, conferring it a variety of functional properties [17-20].

Previously, we proposed a new method for obtaining aqueous sols of nanodisperse solid solutions of cerium dioxide doped with gadolinium ions, with a potential for use in biomedicine [21]. The $\mathrm{Gd}^{3+}$ ion, having 7 unpaired electrons $\left({ }^{8} \mathrm{~S}_{7 / 2}\right)$, is known to possess an exceptionally high magnetic moment $(7.94 \mu B)$, which makes it possible to use gadolinium-containing compounds as contrast agents in the magnetic resonance imaging (MRI) [22]. It is believed that nanocrystalline gadolinium oxide is one of the most promising contrast agents for MRI, since it is characterized by a higher value of the longitudinal relaxation constants compared to the $\mathrm{Gd}^{3+}$ chelate complexes [23]. Meanwhile gadolinium does not participate in the human biochemical cycle and is highly toxic in its ionic form, which eliminates the possibility of its direct biomedical application without additional modification [24]. In existing clinically approved gadolinium-based contrasting preparations, the biological inertness of gadolinium ion is achieved by encapsulating it in macrocyclic complexes [25].

In light of this, the present study aimed to carry out a comprehensive assessment of the cytotoxic properties of a new type of citrate-stabilized cerium dioxide nanoparticles doped with gadolinium on the culture of human mesenchymal stem cells. 


\section{Materials and methods}

\subsection{Synthesis of $\mathrm{Ce}_{0.8} \mathrm{Gd}_{0.2} \mathrm{O}_{2-x}$ nanoparticles}

For the preparation of colloidal solutions of cerium dioxide nanoparticles doped with gadolinium, assuming the sum of rare-earth elements per liter of solvent equal to 0.01 mole, $0.347 \mathrm{~g}$ of $\mathrm{Ce}\left(\mathrm{NO}_{3}\right)_{3} \cdot 6 \mathrm{H}_{2} \mathrm{O}$ and $0.087 \mathrm{~g}$ of $\mathrm{Gd}\left(\mathrm{NO}_{3}\right)_{3} \cdot 5 \mathrm{H}_{2} \mathrm{O}$ (molar ratio $\mathrm{Ce}: \mathrm{Gd}=4: 1$ ) were dissolved in $100 \mathrm{ml}$ of distilled water, and a preliminarily transformed to the $\mathrm{OH}$-form anion exchange resin Amberlite IRA $410 \mathrm{CL}$ was added to the resulting solution until a $\mathrm{pH}=10.0$. The formed sols were separated from the resin by filtration, immediately transferred to $100 \mathrm{ml}$ polytetrafluoroethylene autoclaves (filling degree $\sim 50 \%$ ) and exposed to hydrothermal microwave treatment for 1 hour at $150{ }^{\circ} \mathrm{C}$. After the completion of experiments the autoclaves were removed from the oven and cooled to room temperature in air. Citric acid was added to the resulting aqueous sols of the solid solution of rare-earth oxides to achieve the concentration of $0.01 \mathrm{M}$. According to the X-ray diffraction analysis, the crystal cell parameter for the sample $\mathrm{Ce}_{0.8} \mathrm{Gd}_{0.2} \mathrm{O}_{2-\mathrm{X}}$, determined upon refinement of the crystal structure, is $0.54174(4) \mathrm{nm}$.

\subsection{Preparation of aqueous sols of $\mathrm{Ce}_{0.8} \mathrm{Gd}_{0.2} \mathrm{O}_{2-x}$ nanoparticles and analysis of physico-chemical parameters}

The $0.01 \mathrm{M}$ solution of sol $(1 \mathrm{ml})$ was mixed with $2 \mathrm{ml}$ of isopropyl alcohol $(70 \%)$ and stirred for 30 minutes at $\sim 80{ }^{\circ} \mathrm{C}$. The resulting solution was then centrifuged $(9.000 \mathrm{~g})$ for 10 minutes at $20{ }^{\circ} \mathrm{C}$, the supernatant was removed and the obtained precipitate was redispersed in $500 \mu \mathrm{l}$ of isopropyl alcohol. This sequence was repeated three times. The resulting precipitate was dried at $50{ }^{\circ} \mathrm{C}$ in an oven and then redispersed in $500 \mu l$ of deionized water. The obtained sol was diluted to $\mathrm{pH} 7.2$ with $10 \%$ aqueous ammonia.

The size distribution of nanoparticles in sols was assessed by a dynamic light scattering method using a Beckman Coulter N5 Submicron Particle Size Analyzer (USA). The size distribution was studied for $\mathrm{Ce}_{0.8} \mathrm{Gd}_{0.2} \mathrm{O}_{2-\mathrm{X}}$ nanoparticle dispersions in deionized water, F12 culture medium (HEPES) and F12 culture medium containing $5 \%$ of serum. The micromorphology of nanoparticles was analyzed with the transmission electron microscopy using a Leo912 AB Omega electron microscope at acceleration voltage of $100 \mathrm{kV}$ (magnification up to $\times 500000$ ), the phase composition of the samples was determined by electron diffraction.

\subsection{Cell culture}

Dental pulp stem cells (DPSC) were isolated from the third molar germ extracted for orthodontic indications from a healthy 16-year-old patient. The cells were extracted with DMEM ("PanEko", Russia) containing 200 U/ml penicillin and $200 \mu \mathrm{g} / \mathrm{ml}$ streptomycin ("Life Technologies", USA) with a syringe inserted into the dental apex and further treated with $0.25 \%$ trypsin $-0.02 \%$ EDTA ("Life Technologies", USA) for 30 min at $37{ }^{\circ} \mathrm{C}$. The isolated cells were centrifuged for $2 \mathrm{~min}$ at $1500 \mathrm{rpm}$ and resuspended to a single cell state in the culture medium consisting of DMEM/F-12 (1:1; Life Technologies) with the addition of $10 \%$ fetal calf serum (FCS). The obtained solution was transferred into $25 \mathrm{ml}$ vials and cultured in the $5 \% \mathrm{CO}_{2}$ atmosphere at $37{ }^{\circ} \mathrm{C}$ with the addition of $10 \%$ FCS (HyClone), $100 \mathrm{U} / \mathrm{ml}$ penicillin/streptomycin, 2 mM L-glutamine in DMEM ("PanEko", Russia). When the subconfluent cells state was achieved, the cultured cells were treated with $0.25 \%$ EDTA-trypsin solution, and added to $75 \mathrm{~cm}^{3}$ vials in a ratio of 1:3. Cells were cultured in DMEM/F-12 ("PanEko", Russia) with the addition of $10 \% \mathrm{FCS}, 100 \mathrm{U} / \mathrm{ml}$ penicillin/streptomycin and $2 \mathrm{mM} \mathrm{L-glutamine.} \mathrm{In} \mathrm{our} \mathrm{study,} \mathrm{cell} \mathrm{cultures} \mathrm{of} \mathrm{3-5} \mathrm{passages}$ were used.

\subsection{MTT assay}

The determination of mitochondrial and cytoplasmic dehydrogenases activity in living cells was carried out using a MTT assay based on the reduction of the colorless tetrazolium salt (3-[4,5-dimethylthiazol-2-yl]-2,5diphenyltetrazolium bromide, MTT). [26]. After 24 and 72 hours of culturing cells $0.5 \mathrm{mg} / \mathrm{ml}$ of MTT reagent was introduced into the wells by replacing the culture medium, followed by a standard MTT assay.

\subsection{The differentiated fluorescent staining method}

Assessment of viability of cells cultured in the presence of $\mathrm{Ce}_{0.8} \mathrm{Gd}_{0.2} \mathrm{O}_{2-\mathrm{X}}$ nanoparticles was performed on a Carl Zeiss Axiovert 200 microscope. An L-7007 LIVE/DEAD BacLight Bacterial Viability Kit (Invitrogen) was used for the assay, which includes SYTO 9 fluorescent dye (absorption - $420 \mathrm{~nm}$, emission - $580 \mathrm{~nm}$ ) and propidium iodide (PI) (absorption - $488 \mathrm{~nm}$, emission $640 \mathrm{~nm}$ ). The morphological analysis of the nuclear apparatus after incubation with nanoparticles was performed using a nuclear dye Hoechst 33342 (absorption $361 \mathrm{~nm}$, emission - $486 \mathrm{~nm}$ ) (Invitrogen). The dyes were added to the medium $(1 \mu \mathrm{g} / \mathrm{ml})$ and the plate was placed 
in a $\mathrm{CO}_{2}$ incubator for 15 minutes. Microphotography was performed after washing the cells of the dye with a phosphate-buffered saline.

\subsection{Assessment of the free lactate dehydrogenase level}

The method allows estimation of the cytoplasmic enzyme concentration - lactate dehydrogenase, which is found in the culture medium in case of cell membrane damage. The cells were seeded into 96-wells microplates and cultured for $24 \mathrm{~h}$ in an atmosphere of $5 \% \mathrm{CO}_{2}$ in air at $37{ }^{\circ} \mathrm{C}$. Six hours after seeding the culture medium was replaced with a medium containing $\mathrm{Ce}_{0.8} \mathrm{Gd}_{0.2} \mathrm{O}_{2-\mathrm{x}}$ nanoparticles with concentrations from $10^{-4} \mathrm{M}^{-10}$ $10^{-9}$ M. Cells with added medium, which did not contain $\mathrm{Ce}_{0.8} \mathrm{Gd}_{0.2} \mathrm{O}_{2-\mathrm{x}}$ nanoparticles, were used as a positive control. Wells with cells containing $10 \mu \mathrm{l}$ of Triton X-100 were used as a negative control. The level of lactate dehydrogenase in the culture medium was determined 24 hours after the introduction of the $\mathrm{Ce}_{0.8} \mathrm{Gd}_{0.2} \mathrm{O}_{2-\mathrm{X}}$ nanoparticles in accordance with the manufacturer's protocol (Thermo Scientific ${ }^{\mathrm{TM}}$ Pierce ${ }^{\mathrm{TM}}$ LDH Cytotoxicity Assay Kit). The optical density of the solutions was determined at wavelengths $\lambda=490 \mathrm{~nm}$ and $\lambda=640 \mathrm{~nm}$ using a Microplate Reader Thermo Multiskan Ascent 96 \& 384 photocolorimeter (Thermo Fisher Scientific, United Kingdom).

\subsection{Analysis of proliferative activity of human MSC}

The cells were seeded into 96-wells microplates (Corning Costar, USA) at a density of $10^{4} / \mathrm{cm}^{2}$ and cultured for $12 \mathrm{~h}$ in an atmosphere of $5 \% \mathrm{CO}_{2}$ in air at $37{ }^{\circ} \mathrm{C}$, followed by introduction of $\mathrm{Ce}_{0.8} \mathrm{Gd}_{0.2} \mathrm{O}_{2-\mathrm{X}}$ nanoparticles solutions with various concentration $\left(10^{-4} \mathrm{M}-10^{-11} \mathrm{M}\right)$ by replacing the culture medium. The proliferative activity was analyzed and the number of cells in each well was counted daily for 4 days using a Molecular Devices CloneSelect Imager System Plate Reader.

\subsection{Statistical data analysis}

The experiments were carried out in $3-4$ replicates, analytical determinations for each sample were performed in duplicate. The results of the experiments were compared with the control experiment. The methods of variation statistics were applied to estimate the reliability of results. To assess the statistical significance, the Mann-Whitney $\mathrm{U}$ test was used $(\mathrm{p} \leq 0.05)$. The obtained data was processed using the GraphPad 5.0 and Microsoft Excel 2007 programs.

\section{Results and discussion}

\subsection{Physico-chemical parameters of the studied samples}

According to TEM data, the synthesized $\mathrm{Ce}_{0.8} \mathrm{Gd}_{0.2} \mathrm{O}_{2-\mathrm{X}}$ nanoparticles have an ultra-small size, on the order of $3-5 \mathrm{~nm}$ (Fig. 1a).
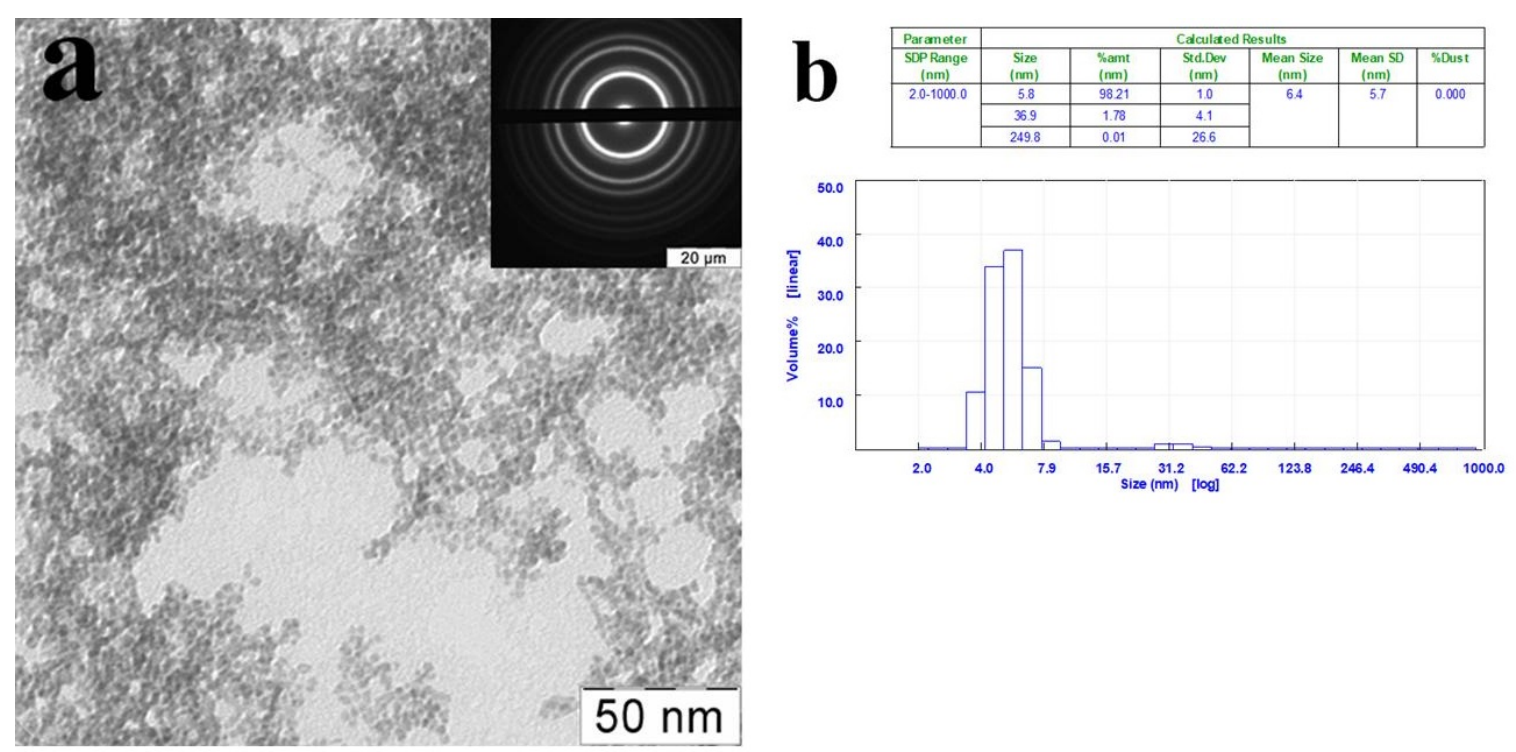

FIG. 1. (a) TEM image of $\mathrm{Ce}_{0.8} \mathrm{Gd}_{0.2} \mathrm{O}_{2-\mathrm{x}}$ nanoparticles; (b) A size distribution histogram of $\mathrm{Ce}_{0.8} \mathrm{Gd}_{0.2} \mathrm{O}_{2-\mathrm{X}}$ nanoparticles upon dilution in a culture medium containing $5 \%$ serum 
Next, the size distribution of the nanoparticles was determined by forming suspensions in deionized water, F12 culture medium (HEPES) and F12 culture medium (HEPES) containing $5 \%$ fetal calf serum. To prepare the suspensions, the sol of $\mathrm{Ce}_{0.8} \mathrm{Gd}_{0.2} \mathrm{O}_{2-\mathrm{X}}$ nanoparticles was diluted 20 -fold by adding a predetermined amount of each solvent. The hydrodynamic radius of nanoparticles in deionized water suspensions was $5.0-7.0 \mathrm{~nm}$, which amounts $95-99 \%$ of the total volume of the suspension. The analysis of the hydrodynamic radius of $\mathrm{Ce}_{0.8} \mathrm{Gd}_{0.2} \mathrm{O}_{2-\mathrm{X}}$ nanoparticles in $\mathrm{F} 12$ serum-free medium showed that the mean size of nanoparticle is $12 \mathrm{~nm}$ $(65.8 \%)$, while in the colloidal solution the micron-size aggregates $(34.1 \%)$ are present.

The dilution of $\mathrm{Ce}_{0.8} \mathrm{Gd}_{0.2} \mathrm{O}_{2-\mathrm{x}}$ nanoparticles in $\mathrm{F} 12$ medium containing FCS provides the monodispersity of the system and the mean hydrodynamic radius of the particles amounts about $6.0 \mathrm{~nm}$, which is $97-100 \%$ of the total volume of the suspension. Earlier it was shown that the negative zeta-potential of nanoparticles surface results in minimal adsorption of proteins (or complete absence of adsorption) on the surface of nanoparticles [27]. Since the layer of citrate ions covering the surface of the nanoparticle provides a negative zeta-potential for the surface, it can be assumed that serum proteins that are partially adsorbed on the surface of nanoparticle, i.e. not forming a "protein corona" of considerable scale, are the size-stabilizing factor for nanoparticles. On the basis of these results, it can be concluded that an interaction with serum proteins does not lead to significant aggregation of nanoparticles, which may allow one to maintain the hydrodynamic radius close to the initial one, for example, after the introduction of nanoparticles into the bloodstream.

TABLE 1. Size distribution analysis of $\mathrm{Ce}_{0.8} \mathrm{Gd}_{0.2} \mathrm{O}_{2-\mathrm{X}}$ nanoparticles after dilution in various biological media

\begin{tabular}{|c|c|c|c|}
\hline Solvent & $\begin{array}{c}\text { Size of } \\
\text { nanoparticles, nm }\end{array}$ & $\begin{array}{c}\text { \% of the total } \\
\text { number in the } \\
\text { sample }\end{array}$ & error, \% \\
\hline \multirow{2}{*}{ Deionized water } & 5.0 & 99.5 & \\
& 51.2 & 0.19 & 0.000 \\
\hline \multirow{3}{*}{ Culture medium F12 } & 987.5 & 0.26 & \\
\hline \multirow{3}{*}{ Culture medium F12 } & 12.1 & 69.21 & \multirow{2}{*}{8.097} \\
$+5 \%$ serum & 2248.4 & 0.59 & \\
& 5,8 & 98.20 & 8,851 \\
\hline
\end{tabular}

\subsection{Study of cytotoxicity of $\mathrm{Ce}_{0.8} \mathrm{Gd}_{0.2} \mathrm{O}_{2-x}$ nanoparticles}

The MTT test was used to assess the viability of human MSCs cultured in the presence of $\mathrm{Ce}_{0.8} \mathrm{Gd}_{0.2} \mathrm{O}_{2-\mathrm{X}}$ nanoparticles. Fig. 2 shows that incubation of human MSCs with $\mathrm{Ce}_{0.8} \mathrm{Gd}_{0.2} \mathrm{O}_{2-\mathrm{x}}$ nanoparticles in the range of concentration from $10^{-5} \mathrm{M}$ to $10^{-9} \mathrm{M}$ does not lead to a decrease in the level of dehydrogenase activity after 24 hours and 72 hours of cultivation. It is worth noting that MTT signal tends to increase in the experiments with micro- and nanomolar concentrations of nanoparticles, which might be associated with the promotion of MSC proliferation in the presence of cerium dioxide nanoparticles doped with gadolinium. An increase in the level of dehydrogenase activity indirectly denotes an increase in the number of viable cells. This confirms the more active proliferation of cells in the presence of $\mathrm{Ce}_{0.8} \mathrm{Gd}_{0.2} \mathrm{O}_{2-\mathrm{X}}$ nanoparticles, which may be due to the effect of nanoparticles on the level of intracellular ROS and, consequently, intracellular signaling pathways. Indeed, our recent publications show that nanoparticles of undoped cerium dioxide are capable of accelerating the proliferation of cells in culture [28-30]. Presumably, one of the mechanisms underlying the stimulation of proliferative activity is the ability of cerium dioxide nanoparticles to act as an effective antioxidant and to reduce the level of intracellular ROS that is slightly elevated under in vitro culture conditions [31].

The analysis of free lactate dehydrogenase level (Fig. 3) in culture of human MSC after co-cultivation of cells with $\mathrm{Ce}_{0.8} \mathrm{Gd}_{0.2} \mathrm{O}_{2-\mathrm{X}}$ nanoparticles did not reveal a significant increase both after 24 hours and after 72 hours, which confirms the absence of cytotoxic effect of nanoparticles over the whole studied range of concentrations. 


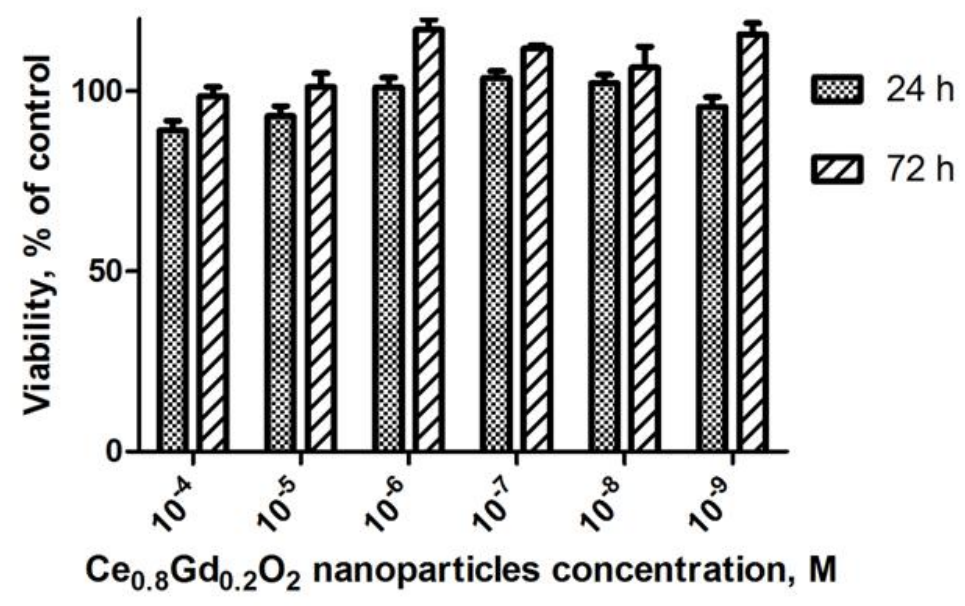

FIG. 2. The analysis of human MSC dehydrogenase activity (in \% of control) according to the MTT test when incubated with $\mathrm{Ce}_{0.8} \mathrm{Gd}_{0.2} \mathrm{O}_{2-\mathrm{X}}$ nanoparticles $\left(10^{-4}-10^{-9} \mathrm{M}\right)$ after 24 and 72 hours of culture

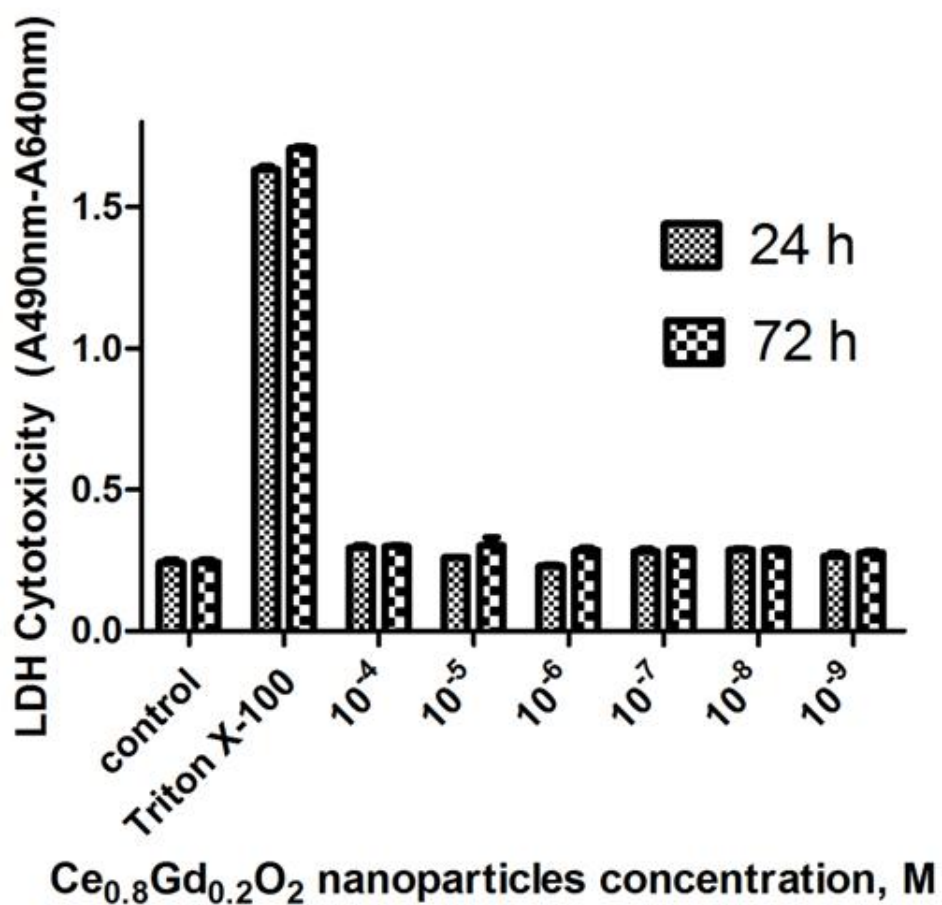

FIG. 3. The analysis of free lactate dehydrogenase level in culture of human MSC after 24 hours and 72 hours of co-cultivation of cells with $\mathrm{Ce}_{0.8} \mathrm{Gd}_{0.2} \mathrm{O}_{2-\mathrm{X}}$ nanoparticles $\left(10^{-4} \mathrm{M}-10^{-9} \mathrm{M}\right)$ 
To estimate the ratio of dead and living cells in the culture of MSC after culturing with the $\mathrm{Ce}_{0.8} \mathrm{Gd}_{0.2} \mathrm{O}_{2-\mathrm{X}}$ nanoparticles, the method of differentiated fluorescent staining was used (Fig. 4). The method is based on the monitoring of viable cells depending on the integrity of their membranes. The SYTO 9 dye stains all the cells in the culture (green staining), while a breach of the integrity of the membrane ensures its permeability to the selective propidium iodide DNA dye (red staining of dead nuclei).

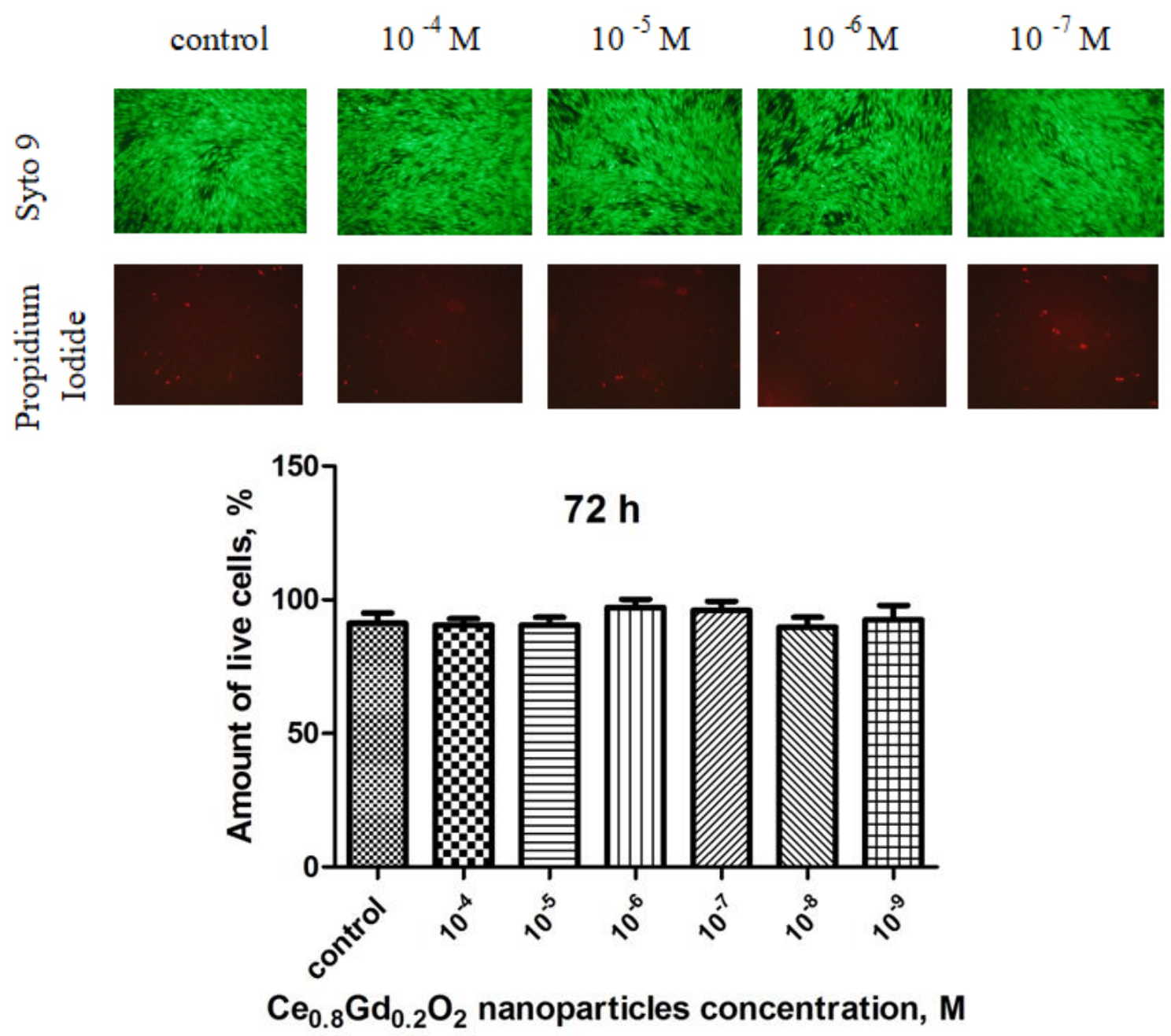

FIG. 4. Microphotographs and a graph of the quantitative estimation of the proportion of viable human MSCs after 72 hours of cultivation with $\mathrm{Ce}_{0.8} \mathrm{Gd}_{0.2} \mathrm{O}_{2-\mathrm{X}}$ nanoparticles $\left(10^{-4} \mathrm{M}-\right.$ $\left.10^{-9} \mathrm{M}\right)$ (staining with L-7007 LIVE/DEAD kit)

We have demonstrated that $\mathrm{Ce}_{0.8} \mathrm{Gd}_{0.2} \mathrm{O}_{2-\mathrm{X}}$ nanoparticles in all studied concentrations $\left(10^{-4} \mathrm{M}-10^{-9} \mathrm{M}\right)$ do not cause the death of cells in culture and the appearance of positive propidium iodide-stained cells. Quantitative assessment of the proportion of viable cells confirmed the absence of a significant difference with the control group, with no introduced nanoparticles.

The morphological analysis of the nuclear apparatus of human MSC (Fig. 5) after cultivation with $\mathrm{Ce}_{0.8} \mathrm{Gd}_{0.2} \mathrm{O}_{2-\mathrm{X}}$ nanoparticles $\left(10^{-4} \mathrm{M}-10^{-9} \mathrm{M}\right)$ showed no increase in the proportion of cells with a damaged or altered nucleus. Both in the control and in the experimental groups with nanoparticles, a significant amount of mitotic division was observed, which confirms the active proliferation of the cell culture. Quantitative assessment of the proportion of cells with a compromised nuclear apparatus did not reveal a significant difference with the control untreated group, which indirectly confirms the lack of genotoxic effect of the $\mathrm{Ce}_{0.8} \mathrm{Gd}_{0.2} \mathrm{O}_{2-\mathrm{X}}$ nanoparticles.

The loss of the mitochondrial membrane potential is a typical feature of the apoptosis development. This is the earliest event in the process of programmed cell death, preceding the externalization of phosphatidylserine to the 

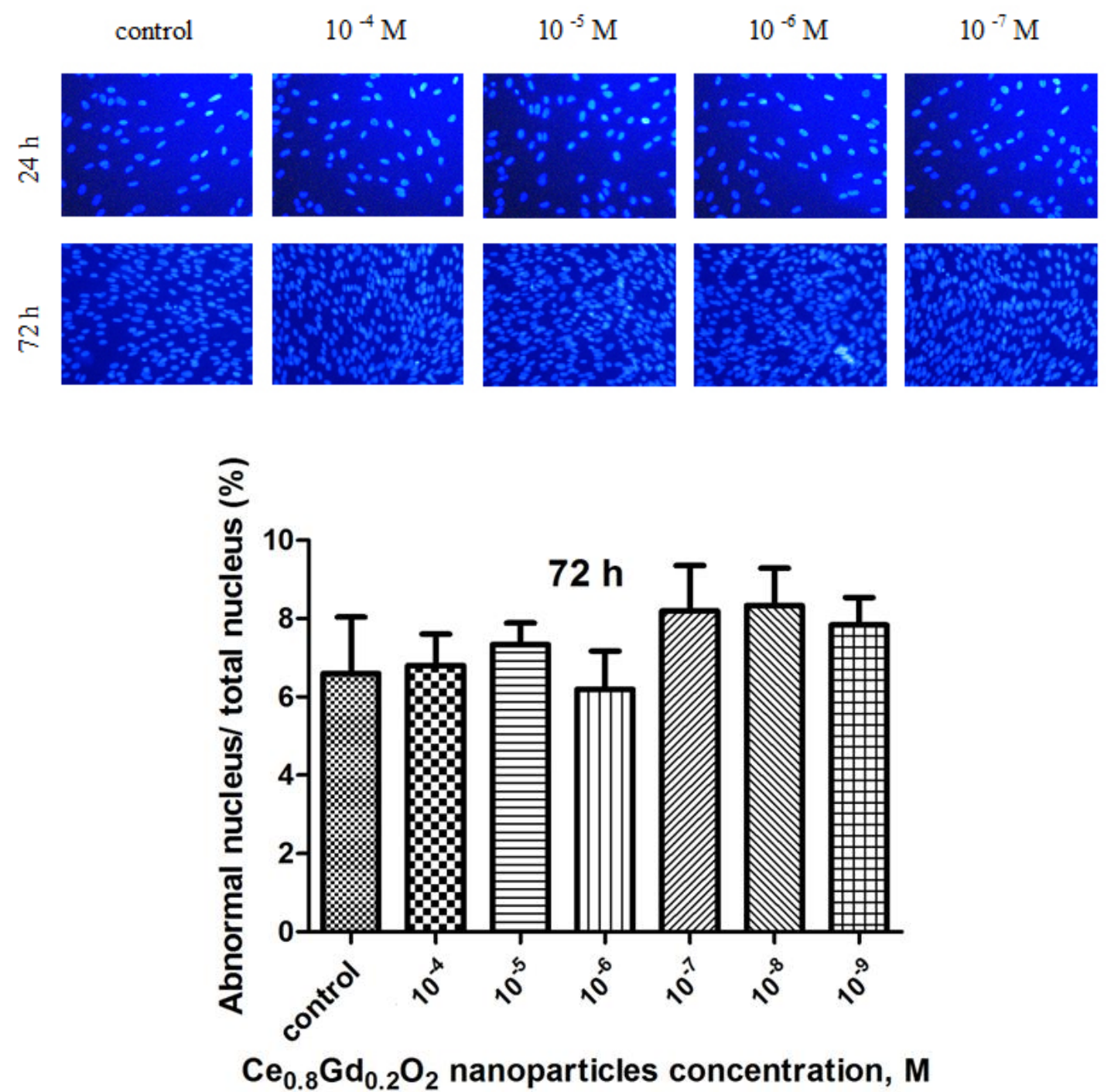

FIG. 5. Micrographs of human MSC after 72 hours of cultivation with $\mathrm{Ce}_{0.8} \mathrm{Gd}_{0.2} \mathrm{O}_{2-\mathrm{X}}$ nanoparticles $\left(10^{-4} \mathrm{M}-10^{-9} \mathrm{M}\right)$ and a quantitative estimation of the proportion of cells with nuclear apparatus abnormalities (fragmentation or change in the morphology of the nucleus) after 72 hours of cultivation (staining with Hoechst 33342)

plasma membrane and coinciding with the activation of the caspase cycle $[32,33]$. The analysis of mitochondrial potential level (Fig. 6) for human MSC after incubation with $\mathrm{Ce}_{0.8} \mathrm{Gd}_{0.2} \mathrm{O}_{2-\mathrm{x}}$ nanoparticles did not reveal its decrease in all studied concentrations $\left(10^{-4} \mathrm{M}-10^{-9} \mathrm{M}\right)$, which confirms the absence of a negative effect on the oxidative phosphorylation processes and the metabolic activity of mitochondria as a whole.

\section{Conclusions}

Thus, in the present work we performed a comprehensive analysis of the cytotoxicity of citrate-stabilized cerium dioxide nanoparticles doped with gadolinium towards human MSC culture. It was demonstrated that $\mathrm{Ce}_{0.8} \mathrm{Gd}_{0.2} \mathrm{O}_{2-\mathrm{X}}$ nanoparticles retain their size within $10 \mathrm{~nm}$ after the dilution in a culture medium containing serum. The $\mathrm{Ce}_{0.8} \mathrm{Gd}_{0.2} \mathrm{O}_{2-\mathrm{x}}$ nanoparticles do not exhibit a cytotoxic effect on human MSC in a wide range of concentrations $\left(10^{-4}-10^{-11} \mathrm{M}\right)$, do not reduce the level of their mitochondrial potential and do not lead to an increase in the proportion of apoptotic cells in the culture. 

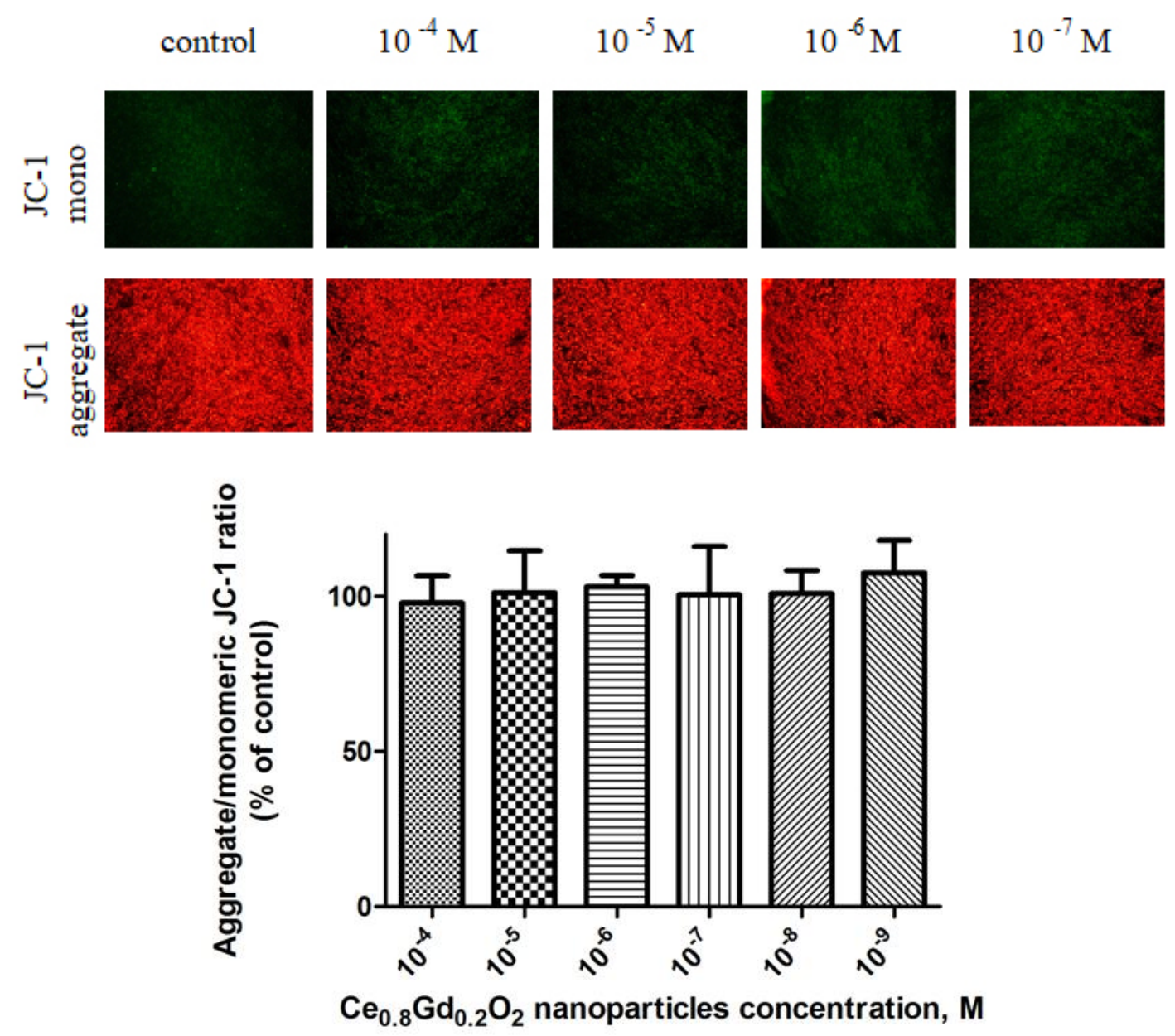

FIG. 6. Microphotographs and a histogram of quantitative assessment of the mitochondrial potential level for the human MSC after 72 hours of cultivation with $\mathrm{Ce}_{0.8} \mathrm{Gd}_{0.2} \mathrm{O}_{2-\mathrm{X}}$ nanoparticles $\left(10^{-4} \mathrm{M}-10^{-9} \mathrm{M}\right)$ (staining with JC-1)

\section{Acknowledgements}

This research has been supported by the Russian Science Foundation (project 17-73-10417).

\section{References}

[1] Khodke M.R., Joshi S.V. An investigative study on application of carbon nanotubes for strain sensing. Nanosystems: Phys., Chem., Math., 2016, 7 (4), P. 755-758.

[2] Suganthi G., Arockiadoss T., Uma T.S. ZnS nanoparticles decorated graphene nanoplatelets as immobilisation matrix for glucose biosensor. Nanosystems: Phys., Chem., Math., 2016, 7 (4), P. 637-642.

[3] Karthikeyan N., Narayanan V., Stephen A. Visible light degradation of textile effluent using nanostructured $\mathrm{TiO} 2 / \mathrm{Ag} / \mathrm{CuO}$ photocatalysts Nanosystems: Phys., Chem., Math., 2016, 7 (4), P. 695-698.

[4] Rokesh K., Jeganathan K., Jothivenkatachalam K. Zinc oxide-palladium material an efficient solar-light driven photocatalyst for degradation of congo red. Nanosystems: Phys., Chem., Math., 2016, 7 (4), P. 740-746.

[5] Mubofu E.B., Mlowe S., Revaprasadu N. Cashew nut shells as source of chemicals for preparation of chalcogenide nanoparticles. Nanosystems: Phys., Chem., Math., 2016, 7 (4), P. 724-727.

[6] Nanjunda Reddy B.H., Venkata Lakshmi V., Vishnu Mahesh K.R., Mylarappa M., Raghavendra N., Venkatesh T. Preparation of chitosan/different organomodified clay polymer nanocomposites: studies on morphological, swelling, thermal stability and anti-bacterial properties. Nanosystems: Phys., Chem., Math., 2016, 7 (4), P. 667-674.

[7] Bobo D., Robinson K.J., Islam J., Thurecht K.J., Corrie S.R. Nanoparticle-Based Medicines: A Review of FDA-Approved Materials and Clinical Trials to Date. Pharm Res. 2016, 33 (10), P. 2373-87.

[8] Popov A.L., Shcherbakov A.B., Zholobak N.M., Baranchikov A.Ye., Ivanov V.K. Cerium dioxide nanoparticles as third-generation enzymes (nanozymes). Nanosystems: Phys., Chem., Math., 2017, 8 (6), P. 760-781. 
[9] Shcherbakov A.B., Ivanov V.K., Zholobak N.M., Ivanova O.S., Krysanov E.Y., Baranchikov A.E., Spivak N.Ya., Tretyakov Y.D. Nanocrystalline ceria based materials-Perspectives for biomedical application. Biophysics, 2011, 56, P. 987-1004.

[10] Ivanov V.K., Shcherbakov A.B., Baranchikov A.E., Kozik V.V. Synthesis, structure, physicochemical properties and biological activity of nanodispersed cerium dioxide. Tomsk, Tomsk State University, 2013.

[11] Ivanov V.K., Shcherbakov A.B., Usatenko A.V. Structure-sensitive properties and biomedical applications of nanodispersed cerium dioxide. Russ. Chem. Rev., 2009, 78, P. 855-871.

[12] Tarnuzzer R.W., Colon J., Patil S., Seal S. Vacancy engineered ceria nanostructures for protection from radiation-induced cellular damage. Nano Lett., 2005, 5, P. 2573-2577.

[13] Karakoti A.S., Singh S., Kumar A., Malinska M., Kuchibhatla S.V.N.T., Wozniak K., Self W.T., Seal S. PEGylated nanoceria as radical scavenger with tunable redox chemistry. J. Am. Chem. Soc., 2009, 131, P. 14144-14145.

[14] Korsvik C., Patil S., Seal S., Self W.T. Superoxide dismutase mimetic properties exhibited by vacancy engineered ceria nanoparticles. Chem. Commun., 2007, P. 1056-1058.

[15] Shcherbakov A.B., Ivanov V.K., Sirota T.V., Tret'yakov Y.D. Inhibition of adrenaline autooxidation by nanocrystalline ceria. Doklady Chem., 2011, 437, P. 60-62.

[16] Das S., Dowding J.M., Klump K.E., McGinnis J.F., Self W., Seal S. Cerium oxide nanoparticles: applications and prospects in nanomedicine. Nanomedicine, 2013, 8, P. 1483-1508.

[17] Ivanova O.S., Shekunova T.O., Ivanov V.K., Shcherbakov A.B., Popov A.L., Davydova G.A., Tret'yakov Y.D. One-stage synthesis of ceria colloid solutions for biomedical use. Doklady Chem., 2011, 437, P. 103-106.

[18] Shcherbakov A.B., Zholobak N.M., Ivanov V.K., Ivanova O.S., Marchevsky A.V., Baranchikov A.E., Tretyakov Y.D. Synthesis and antioxidant activity of biocompatible maltodextrin-stabilized aqueous sols of nanocrystalline ceria. Russ. J. Inorg. Chem., 2012, 57, P. 1411-1418.

[19] Karakoti A.S., Munusamy P., Hostetler K., Kodali V., Kuchibhatla S., Orr G., Pounds J.G., Teeguarden J.G., Thrall B.D., Baer D.R. Preparation and characterization challenges to understanding environmental and biological impacts of nanoparticles. Surf. Interface Anal., 2011, 44, P. 882-889.

[20] Zholobak N.M., Shcherbakov A.B., Bogorad-Kobelska A.S., Ivanova O.S., Baranchikov A.Ye., Spivak N.Ya., Ivanov V.K. Panthenolstabilized cerium dioxide nanoparticles for cosmeceutic formulations against ROS-induced and UV-induced damage. J. Photochem. Photobiol. $B, 2014$, 130, P. 102-108.

[21] Gasymova G.A., Ivanova O.S., Baranchikov A.Ye., Shcherbakov A.B., Ivanov V.K., Tretyakov Yu.D. Synthesis of aqueous sols of nanocrystalline ceria doped with gadolinia. Nanosystems: Phys., Chem., Math., 2011, 2 (3), P. 113-120 (in Russian)

[22] Xiao Y.D., Paudel R., Liu J., Ma C., Zhang Z.S., Zhou S.K. MRI contrast agents: Classification and application (Review). Int. J. Mol. Med., 2016, 38 (5), P. 1319-1326.

[23] Zhou Z., Lu Z.-R. Gadolinium-Based Contrast Agents for MR Cancer Imaging Wiley Interdiscip Rev Nanomed Nanobiotechnol., 2013, 5 (1), P. 1-18.

[24] Ramalho J., Ramalho M., Jay M., Burke L.M., Semelka R.C. Gadolinium toxicity and treatment Magnetic Resonance Imaging, 2016, 34, P. $1394-1398$

[25] Aime S., Barge A., Botta M., Casnati A., Fragai M., Luchinat C., Ungaro R. A Calix[4]arene Gd III Complex Endowed with High Stability, Relaxivity, and Binding Affinity to Serum Albumin Angewandte Chemie International Edition, 2001,40 (24), P. $4737-4739$.

[26] Zholobak N.M., Popov A.L., Shcherbakov A.B., Popova N.R., Guzyk M.M., Antonovich V.P., Yegorova A.V., Scrypynets Y.V., Leonenko I.I., Baranchikov A.Ye., Ivanov V.K. Facile fabrication of luminescent organic dots by thermolysis of citric acid in urea melt, and their use for cell staining and polyelectrolyte microcapsule labeling. Beilstein Journal of Nanotechnology., 2016, 7, P. $1905-1917$.

[27] Patil S., Sandberg A., Heckert E., Self W., Seal S. Protein adsorption and cellular uptake of cerium oxide nanoparticles as a function of zeta potential. Biomaterials, 2007, 28 (31), P. 4600-7.

[28] Popov A.L., Popova N.R., Selezneva I.I., Akkizov A.Y., Ivanov V.K. Cerium oxide nanoparticles stimulate proliferation of primary mouse embryonic fibroblasts in vitro. Materials Science and Engineering: C, 2016, 68, P. 406-413.

[29] Popov A.L., Ermakov A.M., Savinstseva I.V., Selezneva I.I., Poltavtseva R.A., Zaraisky E.I., Poltavtsev A.M., Stepanov A.A., Ivanov V.K., Sukhikh G.T. Citrate-stabilized nanoparticles of $\mathrm{CeO}_{2}$ stimulate proliferation of human mesenchymal stem cells in vitro. Int. J. Nanomech. Sci. Tech., 2016, 7 (3), P. 1-12.

[30] Popov A.L., Ermakov A.M., Savintseva I.V., Selezneva I.I., Poltavtseva R.A., Zaraiskii E.I., Poltavtsev A.M., Stepanova I.E., Ivanov V.K., Sukhikh G.T. Biosafety and effect of nanoparticles of $\mathrm{CeO}_{2}$ on metabolic and proliferative activity of human mesenchymal stem cells in vitro. Int. J. Nanomech. Sci. Tech., 2016, 7 (2), P. 165-75.

[31] Muller F., Lustgarten M., Jang Y., Richardson A., van Remmen H. Trends in oxidative aging theories Free Radic. Biol. Med., 2007, 43, P. 477-503.

[32] Zacharias L.C., Estrago-Franco M.F., Ramirez C., Kenney M.C., Takahashi W.Y., Seigel G.M., Kuppermann B.D. The effects of commercially available preservative-free FDA-approved triamcinolone (Triesence ${ }^{\circledR}$ ) on retinal cells in culture. J. Ocul. Pharmacol. Ther., 2011, 27 (2), P. 143-50.

[33] Gründker C., Föst C., Fister S., Nolte N., Günthert A.R., Emons G. Gonadotropin-releasing hormone type II antagonist induces apoptosis in MCF-7 and triple-negative MDA-MB-231 human breast cancer cells in vitro and in vivo. Breast Cancer Research, $2010,12, \mathrm{P} . \mathrm{R} 49$. 